\title{
POLÍTICAS PÚBLICAS DE AÇÕES AFIRMATIVAS E O SISTEMA DE COTAS RACIAIS
}

\section{ARTIGO ORIGINAL}

MATOS, Milena Menezes ${ }^{1}$

MATOS, Milena Menezes. Políticas Públicas de Ações Afirmativas e o sistema de Cotas Raciais. Revista Científica Multidisciplinar Núcleo do Conhecimento. Ano 05, Ed. 04, Vol. 06, pp. 05-13. Abril de 2020. ISSN: 2448-0959, Link de acesso: https://www.nucleodoconhecimento.com.br/administracao/sistema-de-cotas-raciais, DOI: 10.32749/nucleodoconhecimento.com.br/administracao/sistema-de-cotas

\section{RESUMO}

O presente artigo tem como proposta a análise da relação existente entre as políticas públicas de ações afirmativas e o sistema de cotas raciais. Apresenta-se, inicialmente, um breve contexto histórico do sistema de cotas raciais no Brasil, e posteriormente, estabelece-se uma análise da relação existente entre as políticas públicas e as cotas raciais. Diante disso, o artigo utiliza como base de sua elaboração o método dedutivo e bibliográfico, no qual se busca por meio de livros, artigos e fontes legislativas, pesquisar e examinar o tema proposto.

Palavras-chave: Ações afirmativas, cotas raciais, Políticas públicas.

\section{INTRODUÇÃO}

O presente artigo tem como proposta expor uma breve evolução histórica do sistema de cotas raciais no Brasil. Dito isso, inicialmente, é de suma relevância destacar o conceito do termo "cotas raciais" para melhor compreensão do tema a ser tratado neste artigo. As cotas raciais referem-se a uma espécie de ação afirmativa que foi

\footnotetext{
${ }^{1}$ Graduada em Administração pela Universidade Federal do Espírito Santo (UFES), pós-graduada em Administração Pública pela Universidade Estácio de Sá.
} 
instaurada em alguns países com a finalidade de atenuar as desigualdades sociais, educacionais e econômicas existentes entre raças.

As desigualdades sociais, sejam em razão da raça ou por fatores econômicos, impulsionaram o surgimento de movimentos sociais, estimulando a criação de políticas públicas, como por exemplo, a ação afirmativa, também conhecida como política de reserva de vagas.

No Brasil, as cotas raciais tornaram-se evidentes a partir dos anos 2000, quando universidades e órgãos públicos iniciaram a adoção dessa medida nas realizações dos vestibulares e dos concursos públicos.

A ação afirmativa é uma tentativa de eliminação das desigualdades historicamente acumuladas na sociedade. As políticas de ação afirmativas, como por exemplo, as cotas, têm sido executadas em diversos países. Elas têm sido implementadas com o propósito de dar respostas aos diferentes segmentos da população que por razões diversas foram discriminados em sua inserção social.

O artigo $5^{\circ}$ da Constituição Federal Brasileira de 1988, afirma que "todos são iguais perante a lei, sem distinção de qualquer natureza [...]", dessa forma, para que seja garantido o direito de igualdade na forma da lei, se faz necessário que trate os iguais de maneira igual e os desiguais de maneira desigual, na medida de suas desigualdades, a fim de que a justiça predomine. Nesse contexto, admite-se o emprego de ações afirmativas para garantir a igualdade de oportunidade.

Diante do exposto, o artigo pretende realizar uma breve análise acerca do tema, com o objetivo de proporcionar uma visão mais ampla ao leitor, de modo a possibilitar questionamentos antes da adoção de um posicionamento a favor ou contra às políticas públicas de ações afirmativas. $O$ artigo utiliza como base de sua elaboração o método dedutivo e bibliográfico, no qual se busca por meio de livros, artigos e fontes legislativas, pesquisar o tema proposto. 


\section{CONTEXTO HISTÓRICO DO SISTEMA DE COTAS RACIAIS}

A lei de cotas raciais surgiu, inicialmente, em 1960, nos Estados Unidos, com a imposição em escolas e ambientes de trabalho, com o objetivo de atenuar as desigualdades econômicas e sociais existentes entre brancos e negros.

Segundo Mereles (2016), o cenário da desigualdade social existente entre brancos e negros ocorre em função da diferença de oportunidades. Essa questão, entretanto, está historicamente associada com o período da escravidão.

Pode-se considerar como uma das histórias mais conhecida acerca da escravidão, a abolição da escravatura, assinada pela Princesa Isabel em 1888 por meio da Lei Áurea. No entanto, cabe destacar que o processo de abolição da escravatura não se tratou de uma tarefa fácil. Na época, o sistema financeiro-econômico que predominava há décadas no Brasil, era o sistema de monocultura e de produção latifundiário, e para abolir esse sistema definitivamente demorou.

De acordo com Mereles (2016), no período em que se deu a abolição da escravatura, a população de escravos negros no Brasil não obteve em seu favor garantias por parte do Estado, nem ação de políticas públicas alguma. Essa população teve de procurar casas e oportunidades de emprego em uma sociedade que se caracterizava como racista, na qual não se interessava em dar oportunidades aos negros e, consequentemente, não se preocupava com a criação de mecanismos de inclusão social. Dessa forma, essa população migrou das senzalas para as favelas e as desigualdades foram se tornando cada vez mais crescentes.

Superado esse breve histórico acerca da escravidão e de sua abolição, torna-se necessário compreender por qual motivo se deu o surgimento do sistema de cotas como forma de ingresso nas universidades brasileiras.

Nos últimos anos, o movimento negro vivido no Brasil teve um aumento significativo, visto que tem por objetivo acabar com a discriminação e o preconceito vivido no país. 
Nesse sentido, o governo federal brasileiro, notou a necessidade de implementar ações de políticas públicas a fim de proporcionar uma democracia racial.

Em 1995, Fernando Henrique Cardoso, criou o Decreto 3.531/95 com a finalidade de desenvolver políticas públicas para a valorização da população negra. Com o decorrer dos anos, surgiu uma demanda social reivindicando o ingresso de um maior índice de estudantes pretos nas universidades brasileiras. Diante disso, a fim de atender à demanda social, o governou adotou o sistema das ações afirmativas, espécie de políticas públicas. Essas ações afirmativas caracterizam-se por serem políticas que proporcionam recursos no acesso à educação (cotas raciais), em prol de pessoas que foram discriminadas no passado ou ainda são no presente, em decorrência de pertencerem a grupos marginalizados de forma socioeconômica, com o objetivo de aumentar a participação dos afrodescendentes no ingresso no ensino superior em igualdade de oportunidade.

Em 2012 foi sancionada a Lei № 12.711/2012, denominada como Lei de Cotas, que em seu Art. $3^{\circ}$ institui a sistematização das reservas de vagas e a proporção do número de vagas destinadas às pessoas autodeclaradas pretas, pardas e indígenas segundo o último censo realizado pelo Instituto Brasileiro de Geografia e Estatística (IBGE).

Entretanto, apenas no ano de 2014 que foi adotado o sistema de cotas raciais como forma de ingresso de pessoas afrodescendentes no ensino superior no Brasil. $O$ pioneirismo coube à Universidade Nacional de Brasília (UnB), que providenciou a ação das ações afirmativas para negros no vestibular.

Dito isso, surge uma reflexão ao questionamento de que se a cor ou a raça podem ser considerados métodos válidos como forma de admissão nas universidades do Brasil. Isto é, questiona-se se deve conceder direitos para pessoas pertencentes da mesma raça. Sobre o aspecto da raça, o autor Silva Jr. (2010) afirma que:

Desde os anos de 50, após estudo realizados pela Organização das Nações Unidas, num empreendimento mundial desenvolvido por 
geneticistas, antropólogos, cientistas sociais, biólogos e bio fisiologistas, o termo raça é considerado, ao menos sob o prisma científico, inaplicável a seres humanos. (JÚNIOR, 2010, p. 14)

Ou seja, essa reflexão origina-se do fato de que há uma corrente de pensamento que defende que os seres humanos são considerados iguais sob o ponto de vista científico, logo, indaga-se o porquê então de distinguir uns dos outros, já que são todos da mesma raça. Considera-se que sob o prisma científico esse critério utilizado para diferenciar o ser humano de acordo com a raça torna-se injusto ao tratar de forma desigual as pessoas em situações iguais geneticamente falando.

Nesse contexto, conclui-se que o sistema de cotas raciais para negros e pardos para o ingresso no ensino superior tornou-se um tema polêmico, tendo em vista que para alguns esse sistema caracteriza-se como uma forma de tratamento benéfico em favor de determinado grupo social, o que pode configurar em concessão de vantagens para determinadas pessoas.

\section{POLÍTICAS PÚBLICAS E COTAS RACIAIS}

As políticas públicas visam suprir as demandas oriundas da sociedade, com o objetivo de efetivar o princípio da igualdade, proporcionando igualdade de oportunidades aos menos favorecidos em diversos sistemas, como por exemplo, de saúde, de educação, de lazer etc. Segundo Peters (1986), considera-se política pública, o somatório das atividades desempenhadas pelo governo, que agem diretamente ou através de delegação, e que influenciam a vida dos cidadãos. (apud SOUZA, 2006).

Para Azevedo (2004, p. 30), "O debate sobre as políticas de ação afirmativa, cuja chave-mestre é a cota racial, tem exposto repetidamente uma assertiva: o racismo só pode ser combatido se o Estado reconhecer a existência real das raças no cenário social."

Pode-se citar como exemplo de política pública, a ação afirmativa (AA) que segundo Bergmann (1996, p. 7), conceitua: 
Ação afirmativa é planejar e atuar no sentido de promover a representação de certos tipos de pessoas - aquelas pertencentes a grupos que têm sido subordinados ou excluídos - em determinados empregos ou escolas. É uma companhia de seguros tomando decisões para romper com sua tradição de promover a posições executivas unicamente homens brancos. É a comissão de admissão da Universidade da Califórnia em Berkeley buscando elevar o número de negros nas classes iniciais [...]. Ações Afirmativas podem ser um programa formal e escrito, um plano envolvendo múltiplas partes e com funcionários dele encarregados, ou pode ser a atividade de um empresário que consultou sua consciência e decidiu fazer as coisas de uma maneira diferente. (apud MOEHLECKE, 2002)

Dessa forma, as ações afirmativas são consideradas políticas públicas compostas de medidas especiais de cunho temporário ou não. Essas medidas presumem uma tentativa de reparar as desigualdades vivenciadas e acumuladas ao longo da história por grupos étnicos ou raciais, de modo que amplie e facilite o acesso desses grupos em condições de igualdade de oportunidade com os demais.

Consistem em políticas públicas (e também privadas) voltadas à concretização do princípio constitucional da igualdade material e à neutralização dos efeitos da discriminação racial, de gênero, de idade, de origem nacional, de compleição física e situação socioeconômica (adição nossa). Impostas ou sugeridas pelo Estado, por seus entes vinculados e até mesmo por entidades puramente privadas, elas visam a combater não somente as manifestações flagrantes de discriminação, mas também a discriminação de fundo cultural, estrutural, enraizada na sociedade. De cunho pedagógico e não raramente impregnadas de um caráter de exemplaridade, têm como meta, também, o engendramento de transformações culturais e sociais relevantes, inculcando nos atores sociais a utilidade e a necessidade de observância dos princípios do 
pluralismo e da diversidade nas mais diversas esferas do convívio humano. (GOMES, 2001, p. 06-07)

O que distingue a ação afirmativa das políticas puramente antidiscriminatórias é o desempenho de forma preventiva em favor dos grupos que potencialmente são discriminados, o que pode ser compreendido tanto como uma reparação de seus efeitos como uma prevenção à discriminação. As políticas puramente antidiscriminatórias, por sua vez, atuam apenas mediante conscientização dos indivíduos que porventura podem vir a cometer atos discriminatórios ou através de repressão aos discriminadores.

Em linhas gerais, as cotas raciais são uma espécie de ação afirmativa, isto é, uma política pública específica com o objetivo de dar resposta às demandas sociais existentes na sociedade e podem ser definidas como medidas de inclusão em curto prazo. Destaca-se que elas, a princípio, são extintas após alcançarem o seu objetivo, pois, teoricamente, elas conseguiram atender aos pedidos das demandas sociais.

Dessa forma, a conclusão a que se chega é de que as ações afirmativas são instrumentos de combate às desigualdades presentes em diversos segmentos da sociedade. Ressalta-se que a política de cotas raciais provavelmente, não resolverá, isoladamente, todos os problemas que tratam da discriminação e marginalização de determinados grupos étnicos, sobretudo dos negros, entretanto, essa política estimula o país a uma futura mudança nos hábitos sociais com a perspectiva de inclusão social em condição de igualdade.

\section{CONCLUSÃO}

Conforme o exposto, o presente artigo buscou abordar um paralelo da realidade existente entre as políticas públicas e as cotas raciais, expondo argumentos de doutrinadores e críticos e apresentando o contexto histórico das cotas raciais no Brasil. 
Embora para alguns a cota racial não seja a opção mais ampla e justa para o ingresso de pessoas consideradas afrodescendentes no ensino superior, cabe destacar que essas políticas de ações afirmativas devem ser interpretadas como uma alternativa de política temporária. Desse modo, depreende-se que, o que de fato se faz imprescindível, é que o Estado exerça o seu compromisso de ofertar educação de qualidade de modo igualitário para todos.

Constata-se uma evolução em relação à inclusão social da população negra na sociedade, visto que as cotas raciais deram oportunidades para essa população em condição de igualdade com o demais. Ressalta-se que o cenário atual da inclusão social da população negra ainda está longe do ideal, porém, a adoção de políticas públicas de ações afirmativas, como as cotas raciais, é uma alternativa de gerar oportunidades e uma tentativa de eliminar as desigualdade historicamente acumuladas, mediante o combate às atitudes discriminatórias e do incentivo ao progresso de todos.

\section{REFERÊNCIAS}

AZEVEDO, Celia Maria Marinho de. Anti-racismo e seus paradoxos reflexões sobre cota racial, raça e racismo. $1^{\underline{a}}$ ed. São Paulo: Annablume, 2004, p. 30.

BRASIL. Constituição Federal de 1988. Promulgada em 5 de outubro de 1988. Disponível

em: <http://www.planalto.gov.br/ccivil_03/constituicao/constituicaocompilado.htm> Acesso em: 09 abr. 2020.

BRASIL. Lei no 12.711, de 29 de agosto de 2012. Dispõe sobre o ingresso nas universidades federais e nas instituições federais de ensino técnico de nível médio e dá outras providências. Disponível em: <http://www.planalto.gov.br/ccivil_03/_ato2011-2014/2012/lei//12711.htm> Acesso em: 09 abr. 2020. 
GOMES, Joaquim Benedito Barbosa. Ação Afirmativa \& Princípio Constitucional da Igualdade: o direito como instrumento de transformação social. A experiência dos EUA. Rio de Janeiro: Renovar, 2001, p. 6-7.

JÚNIOR, Hédio Silva. Igualdade. Direito de Igualdade Racial. 1ª ed. São Paulo: Juarez de Oliveira, 2002. p.14.

MERELES, Carla. Cotas Raciais no Brasil. Entenda o que são. Disponível em: http://www.politize.com.br/cotas-raciais-no-brasil-o-que-sao/ Acesso em: 09 abr. 2020.

MOEHLECKE, Sabrina. Ação afirmativa: História e debates no Brasil. Cad. Pesqui., São Paulo, n. 117, p. 197-217, Nov. 2002 . Available from <http://www.scielo.br/scielo.php?script=sci_arttext\&pid=S010015742002000300011\&lng=en\&nrm=iso > access on 09 Apr. 2020.

SOUZA, Celina. Políticas públicas: uma revisão da literatura. Sociologias, Porto Alegre , n. 16, p. 20-45, Dec. 2006 . Available from <http://www.scielo.br/scielo.php?script=sci_arttext\&pid=S1517$45222006000200003 \& \operatorname{lng}=e n \& n r m=i s 0>$. access on 09 Apr. 2020.

Enviado: Abril, 2020.

Aprovado: Abril, 2020. 